\title{
- Community Rights and Tenure in Country Emission Reduction Programs STATUS AND RISKS FOR THE FCPF CARBON FUND
}

$\mathrm{S}$ ince the concept of reducing emissions from deforestation and forest degradation (REDD) was first introduced to the United Nations Framework Convention on Climate Change (UNFCCC) in 2005, significant progress has been made toward defining the contours of such initiatives and strengthening the implementation capacities of participating countries. Today, efforts to reduce forest emissions, improve sustainable forest management, and enhance and conserve forest carbon stocks—activities referred to as REDD+- -are supported by more than 15 UNFCCC decisions ${ }^{1}$ and a wide range of bilateral and multilateral initiatives, including the World Bank-led Forest Carbon Partnership Facility (FCPF), Forest Investment Program, UN-REDD Programme, and various dedicated funds.

As countries shift their attention from REDD+ readiness to implementation, the extent to which anticipated investments will yield effective, equitable, and transparent benefits for forest communities remains an open question. In considering the potential impacts of the FCPF Carbon Fund ("Carbon Fund")—one of the most important donor initiatives supporting verified emission reductions - this study presents a critical assessment of the attentiveness of key countries in the Carbon Fund's pipeline to the rights and livelihoods of Indigenous Peoples and local communities.

Drawing on evidence contained in national Emission Reductions Program Ideas Notes (ER-PINs) and other required submission documents, the study reveals critical gaps in terms of the involvement of forest communities in the planning and implementation of proposed Emission Reductions Programs (ER-Ps) and dedicated actions to recognize and protect their land and resource rights. The study concludes that while participating countries can and should do more to strengthen community engagement and promote tenure reform as part of their respective REDD+ strategies,

\section{Key Findings}

The review of 13 national submissions in the Carbon Fund pipeline paints a mixed picture. Despite clear commitments toward the realization of REDD+ ambitions, all 13 fell short in terms of developing concrete action plans that protect or enhance the rights of the Indigenous Peoples and local communities who are largely responsible for the continued existence and sustainable stewardship of the forests the international community depends upon.

Specifically:

1. The importance of secure tenure rights for effective REDD+ implementation is largely unrecognized, with weak to non-existent commitments to advance such issues within the scope of proposed ER-PS.

2. Locally affected populations and vulnerable groups are inadequately involved in the design and intended delivery of proposed ER-PS.

3. The participation of women and the development of gendersensitive approaches are a struggle for most countries.

4. Most countries lack a legal foundation for carbon rights, rendering problematic the promise of carbon as a tradeable asset.

5. Requirements for establishing fair and equitable benefit sharing schemes are insufficient for developing timely and comprehensive strategies.

6. The governance institutions needed to support transparent, equitable, and effective REDD+ interventions are largely absent from the proposed ER-Ps.

7. Drivers of deforestation and forest degradation are mostly identified, though proposed interventions are not always consistent with the needed actions.

\section{RRI Partners}

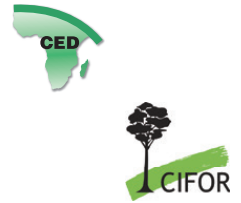

Respic


PRं'̈́'SMA

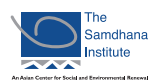


country responsiveness ultimately depends on the requirements of the Carbon Fund itself. To advance the rights and livelihoods of Indigenous Peoples and local communities, changes will need to be made in the standards and safeguards endorsed by the Carbon Fund and sanctioned by the broader REDD+ community.

\section{The Carbon Fund in the context of REDD+}

To support participating countries in developing the policies and systems necessary for REDD+ engagement and eventual implementation of dedicated ER-PS, the FCPF established two distinct yet complementary funding mechanisms: the Readiness Fund and the Carbon Fund, the former of which is meant to prepare countries for the latter.

Since it became operational in 2011, the Carbon Fund has played a key role in the evolution of REDD+. In December 2013, the FCPF adopted a Methodological Framework (MF) composed of 37 criteria and indicators applicable to participating countries' submissions, designed to ensure consistency in the approach used for carbon accounting and other programmatic characteristics. As the first methodological guidance for resultsbased payments under REDD+, the MF sets important precedents for the development of future REDD+ financing options -including bilateral arrangements and a possible REDD+ window in the Green Climate Fund-which could potentially influence how relevant UNFCCC decisions are operationalized in this regard. With the global shift toward REDD+ implementation and the financing demands this will create, it is critically important to understand the normative implications of the existing Carbon Fund architecture.

The MF was developed under the guidance of the FCPF Participants Committee and since its adoption, its design and requirements have raised a number of concerns about the impact on Indigenous Peoples and local communities. These include the complications and implications of a tradable emissions reduction approach in the absence of a well-defined carbon market, and the MF's meager attempts to uphold the rights of forest populations. In effect, the Carbon Fund does not require time-bound action plans to address such concerns, yet calls for the creation of property rights to carbon that risk impinging upon the statutory and customary rights of Indigenous Peoples and local communities, weakening the prospect of equitable benefit sharing with those who have been at the forefront of forest protection efforts.

\section{Why tenure rights?}

For generations, Indigenous Peoples and local communities have sustainably used and protected their forests to meet their needs, all the while conserving and enhancing the forest carbon stocks that are critical to climate change mitigation and adaptation efforts. Recognizing and protecting their rights is the first and most important step toward reducing emissions from deforestation and forest degradation. ${ }^{2}$ Securing tenure rights offers a cost-effective strategy ${ }^{3}$ for combating climate change that also supports the realization of sustainable development goals including poverty alleviation, livelihood enhancement, and biodiversity conservation, ${ }^{4}$ all of which are charter-defined objectives of the FCPF. ${ }^{5}$

The importance of forest communities to climate change mitigation is supported by a growing body of research. Globally, legally recognized community forests contain some 37.7 billion metric tons of carbon, or 29 times the annual emissions of all passenger vehicles in the world, according to a 2014 World Resources Institute and RRI study. ${ }^{6}$ When also accounting for lands that are customarily claimed and legally owned by communities, the collective impact on carbon sequestration is even greater. A 2015 study by the Woods Hole Research Center and the Environmental Defense Fund found that legally recognized and customarily held indigenous territories in four of the most important tropical forest areas in the world (the Amazon Basin, the Mesoamerican region, the Democratic Republic of the Congo, and Indonesia) contain 168.3 gigatons (168.3 billion tons) of carbon dioxide, or more than three times the world's emissions in 2014 . $^{7}$

Globally, however, tenure insecurity undermines the sustained stewardship behind this unparalleled contribution to combating climate change. Indigenous Peoples and local communities have legally recognized ownership rights to less than a quarter of the forest area across 33 low and middle income countries, ${ }^{8}$ which is highly problematic since weak or unenforced community rights are associated with higher rates of deforestation, greenhouse gas emissions, ${ }^{9}$ conflict, and predatory land grabs. ${ }^{10}$ The need to significantly expand the forest area under community ownership and stewardship cannot be overemphasized, as forest populations cannot continue protecting their lands without tenure security to protect themselves. To conserve and enhance the world's forests - as called for in Article 5 of the Paris Agreement-it is imperative that governments begin by securing the rights of those who are largely responsible for the maintenance and protection of these critical greenhouse gas sinks and reservoirs.

To better understand the implications of the Carbon Fund, RRI assessed a sample of ER-PINs and related documents to understand the potential impacts for Indigenous Peoples and local communities.

RIGHTS + RESOURCES INITIATIVE 2 


\section{Methodology}

This study presents the results of a desk review of national ER-PIN submissions to the Carbon Fund and the guidance provided by the MF. Drawing from the 18 ER-PINs that are currently in the Carbon Fund pipeline, a sample of 13 countries was selected on the basis of countries' regional distribution, relative importance to carbon sequestration, and other unique features such as their respective development status and forest governance dynamics. By region, the selected countries are: Côte d'Ivoire, Democratic Republic of the Congo (DRC), Ghana, Madagascar, Mozambique, and Republic of the Congo (RoC) for Africa; Costa Rica, Guatemala, Mexico, and Peru for Latin America; and Indonesia, Nepal, and Vietnam for Asia.

Using the contents of FCPF documents and the resources provided by other relevant studies, ${ }^{11}$ RRI developed an analytical framework to assess the rigor and comprehensiveness of countries' proposed ER-Ps relative to community participation, land and forest tenure, carbon rights, benefit sharing, drivers of deforestation, safeguards, and governance. ${ }^{12}$ The analytical framework consists of 33 indicators examining the extent to which key aspects of these issues are addressed, using a three-tier rating system.

ER-PIN assessments were supplemented by reviews of documents prepared for other phases of the Carbon Fund process completed by April 2016, including the Readiness Preparation Proposal (R-PP); Emission Reductions Program Document (ER-PD); documents from the Readiness Package (R-Package), which includes the Strategic Environmental and Social Assessment (SESA) and the Environmental and Social Management Framework (ESMF); and Mid-Term Reports (MTR). At the time of this study, only Costa Rica and DRC had submitted ER-PDs to the Carbon Fund. ${ }^{13}$

Complete assessments for the 13 countries as well as the analytical framework used for the assessments are available at www.rightsandresources.org/erpins2016. Draft versions of this report were submitted to expert observers, including RRI Partners and Collaborators, for their review and input. This study presents a synthesis of the key findings.

\section{Key findings}

Overall study results showed variation in the extent to which countries' submissions to the Carbon Fund respected the rights and livelihoods of Indigenous Peoples and local communities. Unfortunately, there was a heavy tilt toward countries not fulfilling key commitments to these populations, as shown in Figure 1.

\section{The importance of secure tenure rights for effective REDD+} implementation is largely unrecognized, with weak to non-existent commitments to advance such issues within the scope of proposed ER-Ps.

The importance of tenure security for the realization of REDD+ ambitions is increasingly recognized by key initiatives and participating countries alike, but evidence drawn from this study and RRI's global tenure database makes it clear that such awareness has yet to translate into

\section{Figure 1}

These charts break down how select indicators for the study were met by the 13 countries in their ER-PINs and related documents for the FCPF Carbon Fund. Country-level assessments with analysis of the full set of indicators used for the study can be found at wWw.rightsandresources.org/erpins2016.

\section{The ER-PIN and/or related documents ...}

effectively engaged locally affected populations and vulnerable groups in the design.



defined the land use and land tenure context of proposed ER Program.

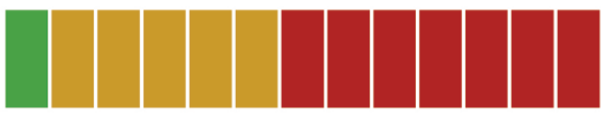

defined a legal framework for carbon rights.

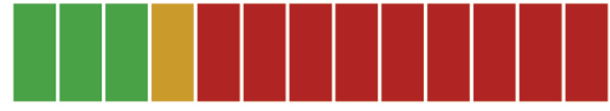

presented a transparent and verifiable process to equitably share non-carbon benefits.

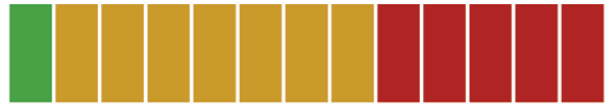

supported the recognition and/or protection of Indigenous Peoples' and local communities' rights.



provided a credible plan for addressing governance issues at national and sub-national levels.

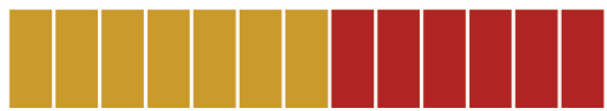

Key

A national submission to FCPF Carbon Fund in which the indicator is clearly addressed and supported by country stakeholders and other sources of evidence.

A national submission to FCPF Carbon Fund in which the indicator is partially addressed and claims are contested, and/or supporting evidence is weak.

A national submission to FCPF Carbon Fund in which the indicator is not addressed or is mentioned but not defined or explained, nor supported by evidence and local stakeholder input. 
dedicated actions and commitments in participating countries. Efforts to clarify tenure relations through structured assessments and participatory vetting processes were weak across the 13 reviewed countries. Six of the countries at least partially defined the land use and land tenure context of their proposals, including implementation risks and arbitration processes, but either failed to produce detailed tenure assessments in the proposed ER-P areas (also referred to as accounting areas or area of intervention) or failed to incorporate the views of affected populations.

Nepal, for example, conducted an independent land tenure assessment in the ER-P area, ${ }^{14}$ in compliance with MF requirements, but whether and how local stakeholder input was taken into consideration was left unspecified. Vietnam provided an overview of land and resources tenure in the selected accounting area, but still had not conducted a tenure assessment at the time of publication. RoC acknowledged that the customary rights of local communities are not recognized and that efforts to do so are hampered by various institutional challenges. Mexico described the land tenure context, but failed to link it to REDD+ and its implications for communities with insecure rights. Madagascar and Guatemala also gave broad overviews of their respective tenure contexts without specifying conditions in their respective ER-P areas. Ghana's ER-PIN did include a description of land use and tenure regimes in the proposed area of intervention, but its claim that "there are no known conflicts of significant scale" in the area is contradicted by a USAID tenure study for the country. ${ }^{15}$ DRC, which is at the ER-PD phase, did not conduct a robust land and resource tenure assessment in the selected accounting area as part of the SESA. With only vague descriptions of the overall context, there has been no progress in its ER-PD regarding land and resources tenure. Costa Rica has also reached the ER-PD phase and conducted a national tenure analysis, but the ER-PD does not describe how or if it was publicly vetted or endorsed. No specific assessment was done as part of its SESA, ER-PIN submission, or ER-PD.

To be fair, nine of the 13 countries had not completed their respective SESAs at the time of the study, which is not required for submission of an ER-PIN and is the point at which tenure-related issues are to be defined. By allowing countries to submit ER-PINs before the tenure situation is assessed and robust safeguards are established, the Carbon Fund risks supporting strategies that may not have been fully vetted and endorsed by affected communities, thereby creating the potential for conflict. While the MF acknowledges the importance of clarifying land and forest tenure as part of any successful ER-P, ${ }^{16}$ the overall logic of the ER-PIN process is not consistent with this view.

The limited consideration of land rights in ER-PIN submissions and the corresponding failure of the FCPF to prioritize tenure as a key requirement for effective and equitable REDD+ initiatives are disconcerting, given that tenure trends in reviewed countries appear to be worsening rather than improving for Indigenous Peoples and local communities (see Figure 2).
Figure 2

Statutory forest tenure in nine of the countries in the study, 2002 and 2013

\begin{tabular}{|c|c|c|c|c|c|}
\hline & \multicolumn{4}{|c|}{ Percent of forest area that is... } \\
\hline & & $\begin{array}{l}\text { government } \\
\text { administered }\end{array}$ & $\begin{array}{l}\text { designated for } \\
\text { Indigenous } \\
\text { Peoples \& local } \\
\text { communities }\end{array}$ & $\begin{array}{l}\text { owned by } \\
\text { Indigenous } \\
\text { Peoples \& local } \\
\text { communities }\end{array}$ & $\begin{array}{l}\text { owned by } \\
\text { individuals \& } \\
\text { firms }\end{array}$ \\
\hline \multirow{2}{*}{ Costa Rica } & 2002 & $40.1 \%$ & $0 \%$ & $12.3 \%$ & $47.7 \%$ \\
\hline & 2013 & $40.4 \%$ & $0 \%$ & $10.3 \%$ & $49.3 \%$ \\
\hline \multirow{2}{*}{ DRC } & 2002 & $100 \%$ & $0 \%$ & $0 \%$ & $0 \%$ \\
\hline & 2013 & $100 \%$ & $0 \%$ & $0 \%$ & $0 \%$ \\
\hline \multirow{2}{*}{ Guatemala } & 2002 & $42.1 \%$ & $12.6 \%$ & $6.9 \%$ & $36.4 \%$ \\
\hline & 2013 & no data & $10.4 \%$ & no data & no data \\
\hline \multirow{2}{*}{ Indonesia } & 2002 & $98.3 \%$ & $0.2 \%$ & $0 \%$ & $1.5 \%$ \\
\hline & 2013 & $96.1 \%$ & $1 \%$ & $0 \%$ & $2.9 \%$ \\
\hline \multirow{2}{*}{ Mexico } & 2002 & $5 \%$ & $0 \%$ & $79.9 \%$ & $15.1 \%$ \\
\hline & 2013 & $4.4 \%$ & $0 \%$ & $69.8 \%$ & $25.8 \%$ \\
\hline \multirow{2}{*}{ Nepal } & 2002 & $81.6 \%$ & $18.4 \%$ & $0 \%$ & $0 \%$ \\
\hline & 2013 & $68 \%$ & $32 \%$ & $0 \%$ & $0 \%$ \\
\hline \multirow{2}{*}{ Peru } & 2002 & $76.7 \%$ & $2.1 \%$ & $14.1 \%$ & $7.1 \%$ \\
\hline & 2013 & $71.2 \%$ & $4.8 \%$ & $21.3 \%$ & $2.7 \%$ \\
\hline \multirow{2}{*}{$\begin{array}{l}\text { Republic of } \\
\text { the Congo }\end{array}$} & 2002 & $98 \%$ & $2 \%$ & $0 \%$ & $0 \%$ \\
\hline & 2013 & $97.9 \%$ & $2.1 \%$ & $0 \%$ & $0 \%$ \\
\hline \multirow{2}{*}{ Vietnam } & 2002 & $100 \%$ & $0 \%$ & $0 \%$ & $0 \%$ \\
\hline & 2013 & $97.8 \%$ & $2.2 \%$ & $0 \%$ & $0 \%$ \\
\hline
\end{tabular}

SOURCE: Rights and Resources Initiative. 2014. What Future for Reform? Progress and slowdown in forest tenure reform since 2002. Washington, DC: RRI. Available at http://rightsandresources.org/en/publication/what-future-for-reform. 
Irrespective of the Carbon Fund's weaknesses in this regard, nothing prevents a submitting country from addressing tenure in its ER-PIN and thus establishing the necessary precedents for more informed engagement. Peru's ER-PIN, for instance, is largely based on securing Indigenous Peoples' and local communities' land rights despite not having begun the SESA. Such examples demonstrate that it is possible to proactively address tenure in the early stages of ER-P formulation, and the data in Figure 2 clearly indicate the urgency of doing so.

\section{Locally affected populations and vulnerable groups are inadequately involved in the design and intended delivery of proposed ER-Ps.}

Full and effective participation of Indigenous Peoples and local communities in the design, implementation, and monitoring of ER-Ps has rightly assumed a central place in REDD+ discourse and safeguard frameworks. ${ }^{17}$ Open and participatory measures are essential for establishing transparent and accountable conditions for REDD+ programming.

Results of this review, however, paint a less positive picture. Evidence of effective community engagement in the planning and design stages was observed in three of the 13 selected ER-PINs, and of these, only two countries presented clear and realistic approaches for securing community involvement in the realization of their proposed ER-PS. Overall, the contributions of forest communities to the proposed emission reduction programs were limited.

As critical constituencies in the global struggle to combat climate change, Indigenous Peoples and local communities have, for generations, protected and sustainably managed significant portions of the world's tropical forests. Many of them depend directly on these ecosystems for their livelihoods, giving them an unparalleled familiarity with the lands whose protection the international community is grappling with. Strong empirical evidence shows that coping with uncertainty in a complex and dynamic world requires place-based knowledge and localized decision-making structures that can quickly adjust to changing social and environmental conditions. ${ }^{18}$ Through their locally adapted institutions, forest communities have, by and large, developed vast repertoires of knowledge and skills for coping with change on the ground, including techniques for managing and conserving forests, water, and soil resources. ${ }^{19}$

While outreach to civil society and Indigenous Peoples' representatives appears to be improving, opportunities for effective engagement remain limited overall. More often than not, participatory platforms take the form of rushed information sharing sessions with limited timeframes for providing feedback on highly technical documents that are seldom translated into local languages. Processes tend to be concentrated in capital cities, with limited involvement of subnational stakeholders due to capacity constraints. Whether collected inputs are then taken into consideration is often unclear. With respect to the development of ER-PINs themselves, reports from the field indicate that local participation tends to be coordinated by a limited number of organizations, with international NGOs often assuming more prominent roles than warranted.

Unfortunately, many countries appear to confuse participation with mere information sharing. For example, Ghana, Guatemala, Indonesia, Mexico, Mozambique, and RoC identified key community and civil society representatives, but generally remained vague on their concerns and intended role or contributions in the realization of ER efforts. Similar "consultations" with civil society were highlighted by Côte d'Ivoire, DRC, and Madagascar, though the implications of these discussions were not addressed. The extent to which established multi-stakeholder bodies have effectively participated in preparation of the ER-PINs is not well documented in most cases, and feedback from community representatives suggest that relevant processes have not been as inclusive as hoped.

Countries that fared better on community participation also tended to be clearer in terms of their approaches to stakeholder engagement. Costa Rica's ER-PIN contained evidence of Indigenous Peoples' and local communities' participation during the readiness phase, including dialogues between appointed officials and indigenous organizations. Peru's ER-PIN built on established processes to present a detailed timetable of activities by year along with a plan for reaching remote communities. Nepal's ER-PIN evidenced ongoing engagement of Indigenous Peoples and local communities, with a number of identified civil society partners, though not all activities proposed by stakeholders were carried out, and there was not a clear timeline for consultation activities.

Finally, free, prior, and informed consent (FPIC) is not explicitly endorsed by the MF, despite broad international agreement on the need for such protocols and the existence of UN-REDD-developed operational guidelines for the application of such principles across REDD+ investments. The Guiding 
Principles, approved by the FCPF Participants Committee, do include a proviso that commits the World Bank to supporting country implementation of FPIC where the country has decided to do so, but the application of such principles was uneven across selected ER-PINs. Though several countries referred to FPIC in their ERPINs, none provided a methodology explaining how this would be pursued in the context of their respective ER-PS and there is no evidence that the World Bank is supporting the development of FPIC methodologies.20

\section{The participation of women and the development of gender-sensitive approaches are a struggle for most countries.}

Men and women typically have different but complementary relationships to forests, providing each with unique knowledge and perspectives to inform decisions about the future of their lands. As described in a report by RRI and the Center for International Environmental Law, women are the primary users of forests for their livelihoods as well as to support their families. ${ }^{21}$ A Center for International Forestry Research study of 77 villages in six countries found that for the most part, a standard gendered division of labor held true for the forest communities, with women carrying out a range of activities -including the collection of firewood, fruits, and vegetables - while men tended to hunt and collect poles. Men tend to be more involved in commercialization and formal markets while women tend to be tied to household and subsistence uses and be more involved in informal markets. ${ }^{22}$ While these activities involve different sets of skills and expertise, they both entail intimate knowledge of the forest and a commitment to their health and future.

Despite the specific needs of women and their importance to sustainable forest governance, efforts to ensure their meaningful participation in the planning and design of ER-Ps were found lacking across reviewed countries' submissions. The documents largely presented aspirational goals for the involvement of women rather than actual evidence of their participation. This was also the case for countries that otherwise scored highly on community participation indicators.

\section{Box 1}

\section{WHY IS GENDER SUCH A CHALLENGE FOR REDD+? Insights from the FCPF Women's Observer}

There is increasing recognition that women in forest communities are central to the success of REDD+, but evidence drawn from this and other studies points to critical gaps in terms of their involvement in the planning, design, and implementation of ER-PS. According to Cécile Ndjebet, president of the African Women's Network for Community Management of Forests (REFACOF) and the first Women's Observer to the FCPF, two critical issues affect the participation of women in REDD+ processes.

First, the role of women in forest communities is poorly understood or inadequately appreciated, both at the country level and across the institutions that support REDD+ initiatives. To address this problem, Ndjebet calls for the systematic use of gender analyses: "A gender analysis helps you understand who to target, their problems, their needs, what can be done to address these." Such analyses are essential, she adds, "to better understand the real challenges REDD+ should be addressing."

The second and perhaps more challenging issue concerns overcoming inequitable cultural norms and practices. "The first people we have to deal with are traditional chiefs. They are responsible for perpetuating the customs. Let's start a dialogue with them," said Ndjebet. She suggests that the FCPF can play a critical role in this regard by partnering with organizations and actors on the ground who are working to change unfavorable customs and attitudes, and create more open and participatory spaces for women. Providing financial and technical support would allow women's groups to expand their activities and be more influential.

Ndjebet credits the FCPF with creating the Women's Observer seat and approving a budget for gender activities for FY17, but believes additional changes such as these could go a long way in making REDD+ projects beneficial to everyone.

To their credit, a number of countries acknowledged the challenges of developing gender-inclusive ERPrograms. Costa Rica, for instance, indicated that women had little voice in the consultation process and REDD+ context itself despite their presence at related events; the country has taken steps to address this by presenting a policy framework in its SESA to improve women's participation. Guatemala's ER-PIN references participation by at least two women's organizations, but similar to the mention of Indigenous Peoples and local community groups in its submission, it was not clear how women's concerns and inputs would eventually be taken into consideration. Ghana has developed, with the support of the International Union for the Conservation of Nature, a roadmap for mainstreaming gender considerations in REDD+ processes and programming. 
In addition to country-level difficulties in recognizing the role and unique needs of women, the MF also came up short in this regard. Notably, gender-specific language is provided in only two places: Indicator 30.1, which requires that benefit sharing systems be gender inclusive; and Indicator 34.1, which calls for gender-inclusive approaches to the allocation of priority non-carbon benefits. In comparison, gendersensitive language was more clearly presented in readiness documents, including the R-PP template, stakeholder engagement guidelines, and the SESA and ESMF guidance. The FCPF clearly needs to do a more comprehensive job of adopting stringent gender protocols, as emphasized in Box 1.

\section{Most countries lack a legal foundation for carbon rights, rendering problematic the promise of carbon as a tradeable asset.}

The right to carbon is a difficult issue to grasp. Working from the premise that a post-2012 compliance market for carbon would be established, the FCPF has persistently viewed carbon rights as a distinct asset that can be disentangled from the complex bundles of rights associated with land, forests, and other natural resources or ecosystem services. ${ }^{23}$ As the Carbon Fund prepares to buy emission reduction units from countries that either disregard overlapping land claims or repeatedly fail to protect customary rights, ${ }^{24}$ there are concerns that governments will simply choose to nationalize carbon rights as a practical way forward, thereby weakening the prospects of much needed tenure reform for forest communities in REDD+ countries.

Legal frameworks governing the ownership and transfer of emission reduction units can help clarify some of the ambiguity that will inevitably arise with a carbon market, but this study found that most of the reviewed countries have not yet established a robust legal structure for the international sale of carbon assets. Of the 13 countries, only four demonstrated progress toward the development of legal frameworks to support the ownership and transfer of forest carbon emission reductions as a new asset class (though not a requirement for ER-PINs). Even then, pending issues remain in all cases, with no countries claiming to possess a fully operational and transparent system, including a process for dealing with contested or overlapping claims. The ER-PIN for Peru, for example, described policy actions for dealing with tenure disputes, but does not describe a specific process for dealing with carbon rights.

While some countries failed to discuss the issue of carbon rights in their ER-PINs altogether (e.g. Ghana, Indonesia, Madagascar, and Vietnam), others referenced the existence of regulatory measures in the R-PP or ER-PIN but failed to provide evidence of actual implementation (e.g. Côte d'Ivoire, Mozambique, and RoC). Nepal's ER-PIN states that the Forest Act of 1993 provides carbon rights to communities, but this claim is not supported in its SESA. The overall lack of clarity in ER-PINs regarding the issue of carbon rights points to unresolved structural problems.

Though troubling, these observations are not surprising given the MF's stance on carbon and what it means for forest communities. As made clear in MF Indicators 36.1 and 36.2, the legal transfer of emission reductions titles can be accomplished by enacting a law, regulation, or decree granting governments the authority to make such transfers, "while respecting the land and resource tenure rights of the potential rights-holders, including Indigenous Peoples...." But if this proves to be too onerous, Indicator 36.2 goes on to state that the authority to transfer such titles can also be conferred through sub-arrangements or benefit sharing agreements with rights-holders in the accounting areas. Given the information asymmetries and power dynamics typical of government-community relations-not to mention the absence of robust FPIC requirements in the Carbon Fund's overall approach-such guidance is unlikely to enhance the ability of affected communities to negotiate fair exchange values. The MF creates a disincentive to solve tenure issues or develop equitable benefit sharing agreements based on clear legal rights.

Collectively, these observations cast doubt over the proposition that carbon rights can be disentangled from actual rights to land and forests. Indigenous Peoples' and local communities' organizations have consistently argued that selling carbon credits would necessarily impinge on their ability to pursue traditional or customary activities, including forestry, farming, and other land uses that could be affected by ER-PS. By treating carbon rights as a tradable asset that can be purchased and transferred separately from other forest rights, the Carbon Fund risks undermining the rights of forest communities in the selected accounting areas and more broadly at the national level. In a context where the emergence of an international forest carbon market is uncertain and the vast majority of the Carbon Fund's emission reduction credits stem from official development assistance, the overall rationale, appropriateness, and efficiency of FCPF's model appears increasingly out of sync with the realities countries must confront, and the needs of forest communities in particular. 


\section{Requirements for establishing fair and equitable benefit sharing schemes are insufficient for developing timely and comprehensive strategies.}

The promise of results-based financing is central to the FCPF and the global REDD+ agenda. Today, the concept of incentivizing sustainable forest use and conservation outcomes is more widely accepted; however, evidence drawn from assessing countries' submissions suggests the question of equitable benefit sharing remains a far more challenging proposition to define, plan, and implement.

Within the MF, mechanisms for sharing carbon benefits (i.e. revenue streams from the sale of ERs) are discussed in Section 5.2 and Criteria 29 to 33. Collectively, these call for: (i) a description of the benefit sharing mechanism; (ii) information on eligible beneficiaries; (iii) establishing linkages between benefit distribution, emission reduction efforts, drivers, as well as land and resource tenure rights; (iv) consultative, transparent, and participatory processes that are inclusive of indigenous and local views; ( $v$ clear reporting processes; and (vi) the recognition of the national legal context and other international commitments. Similarly, for non-carbon benefits, the MF states that these should be integral to all ER-Ps approved for financing and admission to the Carbon Fund pipeline (Criterion 34), build on safeguards plans, include the expected results of the ER-P, ${ }^{25}$ and require the joint identification of priority non-carbon benefits with key stakeholders.

Of the 13 countries reviewed, Costa Rica and Guatemala presented transparent and verifiable processes to equitably share carbon and non-carbon benefits. While some countries presented relatively clear strategies for sharing carbon benefits (i.e. Mexico and Vietnam), nearly all reviewed countries failed to present detailed information on non-carbon benefits. This is not surprising, given the Carbon Fund's insistence on results-based payments for carbon over the realization of other potential non-carbon benefits, and the resistance to paying for non-carbon benefits even if this is technically allowed for by the MF.

The benefit sharing schemes outlined in countries' submissions often went against the best interests of affected communities, suggesting that transparent community engagement and endorsement of these schemes was not a part of the process. In the case of DRC (which is explored more closely in Box 2), for instance, the proposed carbon benefit sharing mechanism foresaw emission reduction credits to legally entitled stakeholders, likely excluding Indigenous Peoples and local communities who lack secure legal land rights from ongoing carbon revenues. Mozambique did not clearly define its approach, but indicated that it would anchor its benefit sharing scheme on its existing legal framework for wildlife and forestry exploration revenues. Indonesia and Nepal failed to present thorough plans with clear provisions grounded in verifiable stakeholder involvement.

Overall, countries that provided clearer benefit sharing plans had initiated broad community engagement, as required by MF Indicator 31.1. However, because the MF allows proponents to submit their final benefit sharing plan after an ERPA is signed, many appear inclined to postpone the complex and often politically-charged benefit sharing discussions to later, resulting in poorly developed or incomplete plans. While this may prevent raising unreasonable expectations, success depends in part on whether and where FPIC is implemented and on the degree of trust between key stakeholders and government. To this end, only Mexico outlined a benefit sharing mechanism that was broadly supported by Indigenous Peoples, local communities, and women. Vietnam's ER-PIN stated that benefit sharing consultations took place at the national, subnational, and local levels, but it did not present the content of these.

\section{The governance institutions needed to support transparent, equitable, and effective REDD+ interventions are largely absent from the proposed ER-Ps.}

The need to develop or reform national and subnational governance institutions to ensure crosssectoral coordination, reduce corruption risks, support stakeholder engagement, apply social and environmental safeguards, eliminate perverse incentives, strengthen transparency, improve access to information, and carry out thorough monitoring of government actions were central elements of the readiness phase. As countries shift their attention from readiness to implementation, it would be fair to expect that institutional competencies for effective REDD+ governance have either been established or are actively being pursued as part of the proposed ER-P. Unfortunately, study results point to widespread challenges in these regards, with limited evidence of core governance competencies across reviewed country submissions. 


\section{THE CONTEXT OF REDD+ IN DRC}

As it moves from ER-PIN to ER-PD, DRC exemplifies the complex social and environmental realities greeting REDD+ implementation. Its performance was generally in line with other countries of the region, but the localized context lends more insight into some unique challenges. Given that DRC holds the world's second-largest forest area after the Amazon and fourth-largest carbon reservoir, the country has attracted considerable attention from REDD+ actors. While this gives it the opportunity to become a regional and global leader, it also raises the stakes for implementation and highlights just how crucial reforms in tenure and resource rights will be as more REDD+ support pours into the country.

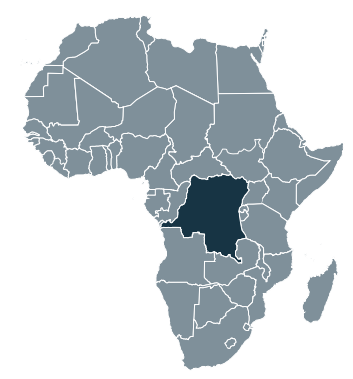

Social and gender considerations were an issue from the beginning. A government working group comprised of representatives from 17 ministries was formed in 2011, but saw its social and gender issues group dissolve due to a lack of resources. As a result, the inclusion of vulnerable groups and women was sporadic and inconsistent during the ER-PIN design. Furthermore, prior studies that informed the submission were silent on issues of gender, including studies on benefit sharing, drivers of deforestation, and reports on ESMF and SESA. The only instrument that referred to gender and social aspects dealt with family planning. Despite these shortcomings, opportunities to mainstream gender will arise with the implementation of a 2015 gender parity law, which will affect REDD+ decision-making bodies at the national, provincial, and local levels.

All forested areas remain government administered. Despite provisions recognizing customary tenure in DRC's forest code and the recent decrees creating the framework for local communities' forest concessions, there are no officially recognized or titled indigenous or community lands in DRC as of yet (as illustrated in Figure 2). In addition to the fact that the decree makes no mention of Indigenous Peoples' rights, local observers note that in general, there is an unclear, overlapping, and conflictive situation between the customary and statutory tenure systems, creating a highly uncertain and risky terrain on which to build a REDD+ program.

The country is moving toward state ownership of carbon rights. This leaves in question the extent to which communities will benefit from carbon revenues, especially in a context marked by insecure land rights. Carbon benefits are slated to be shared with "project holders" while Indigenous Peoples and local communities are to receive carbon and non-carbon benefits that are de-linked from carbon performance. This can be positive in that it recognizes the historic stewardship of forest communities and is not based on activities they had little say in implementing, but can also be unsustainable because of the lack of steady revenue streams.

In terms of coordination among sectors, line ministries, and levels of government, only Costa Rica provided detailed evidence of effective inter-institutional links. While the challenges of government coordination are recognized in many ER-PINs, efforts to solve this core institutional dilemma have so far been met with limited success. In most countries, the ministry or department charged with REDD+ coordination efforts-usually the environment or natural resources ministry-also tends to be among the weakest in terms of administrative capacity, budget, and authority. As a result, its ability to coordinate with others is often limited, even if mandated by decree or national policy. When combined with the territorialism and rent-seeking behaviors inherent to any silo-ed government structure, it is clear that many barriers need to be confronted if inter-sectoral approaches are to emerge.

Strongly correlated to the issue of governance are the risks of corruption, limited transparency, and poor oversight. In spite of the inevitable nature of corruption risk, especially in countries marked by weak governance institutions, effective anti-corruption measures were noticeably absent from nearly all of the submissions. Of the 13 countries, only Ghana and Mexico partially addressed corruption 
risks in their ER-PINs or related submission documents. While Ghana acknowledged the potential for corruption, efforts to address this were limited to oversight considerations within its benefit sharing approach. Mexico was more explicit, referencing the anti-corruption measures it adopted as part of its institutional safeguards.

Countries' capacities to effectively and transparently monitor the use of financial resources, the social and environmental impacts of projects, the application of safeguards, and the distribution of benefits were ostensibly weak across nearly all reviewed submissions. Only one country, Guatemala, provided clear evidence of an open-access information management system for REDD+; two, Costa Rica and Peru, presented thorough plans to monitor the social and environmental impacts of REDD+ investments; one, Costa Rica, clearly defined how governance-related interventions would be monitored; and one, Mexico, provided plans for monitoring the distribution of carbon and non-carbon benefits.

Finally, in terms of the development of a comprehensive safeguards framework, progress was altogether inadequate for protecting the land and resource rights of Indigenous Peoples, local communities, and women. At the time of this review, only four countries_DRC, Mexico, Costa Rica, and Nepal-had completed the SESA. The study found compelling evidence that social and environmental issues were assessed in a transparent and participatory manner for Mexico and Costa Rica, whereas only four countries had partially developed credible grievance/dispute resolution mechanisms and safeguard information systems.

\section{Drivers of deforestation and forest degradation are mostly identified, though proposed interventions are not always consistent with required actions.}

Analyses of drivers of deforestation and forest degradation were also a mixed picture. While direct drivers such as infrastructure development, agro-industrial expansion, and illegal logging are generally identified, proposed interventions tend to ignore the political and economic forces behind such drivers. Consequently, instead of developing strategies to deal with the policies, subsidies, and regulatory failures that underpin most of the large-scale land use and land cover changes in the world today, ${ }^{26}$ attention tends to be unevenly tilted toward lower-level concerns that unfairly burden or target Indigenous Peoples and local communities. To be sure, poor governance (including insecure land rights), weak enforcement, and policy incoherence are discussed, but convincing strategies to address these issues remain wanting across most of the reviewed submissions.

With the exception of DRC and Indonesia, drivers were identified in submissions but many lacked spatially explicit data, relied on information that was not always up-to-date, ${ }^{27}$ or demonstrated limited involvement of Indigenous Peoples and local communities in identifying key drivers. In some cases, like Madagascar, communities were blamed for ongoing deforestation trends, which resulted in strategies to curb traditional activities as opposed to more fundamental issues like insecure land rights. Though insecure tenure was identified as an underlying driver of deforestation by some (notably DRC, Indonesia, and Peru), only Peru committed itself to addressing this issue in its submission. Countries were mostly successful in defining key challenges associated with stated drivers, with well-supported evidence from Côte d'Ivoire, Costa Rica, Peru, RoC, and Vietnam. Finally, Vietnam was the only country whose submission sufficiently aligned its ER-P strategies with the main drivers of deforestation.

The MF could do more to strengthen requirements for countries to make more systematic links between proposed REDD+ efforts and the main drivers of deforestation in the proposed ER-P area. Although Criterion 27 of the MF requires submitting countries to describe how their programs will address identified drivers of deforestation and forest degradation, nothing prevents proponents from being selective in the choice of drivers that will be targeted.

\section{Conclusion and recommendations}

This study of ER-PIN and other submission documents from 13 key forested countries in the Carbon Fund pipeline paints a mixed picture, as depicted in Figure 3. Despite making clear commitments to climate change mitigation and adaptation via the implementation of REDD+ initiatives, all 13 fell short in terms of developing concrete action plans to carry out these goals in a responsible, transparent, and participatory manner. Ultimately, the challenge of developing emission reduction strategies that can enhance equity, support the achievement of sustainable development goals, and help reduce poverty depends on the active involvement and engagement of forest communities. The FCPF has 47 participating countries, and the 18 that have submitted ER-PINs thus far are generally farther along in their respective REDD+ processes than the others. If the 13 countries whose ER-PINs and other 


\section{Figure 3}

This table shows how the 13 countries in the study performed on select indicators related to community participation, land tenure and resource rights, benefit sharing, and forest governance in their ER-PINs and related documents for the FCPF Carbon Fund. Country-level assessments with analysis of the full set of indicators used for the study can be found at www.rightsandresources.org/erpins 2016.

The country's ER-PIN and/or related documents ...

effectively engaged locally affected populations and vulnerable groups in the design.

defined the land use and land tenure context of proposed ER Program.

defined a legal framework for carbon rights.

presented a transparent and verifiable process to equitably share non-carbon benefits.

targeted the main drivers of deforestation and forest degradation with proposed interventions.

clearly identified opportunities for community-based interventions and investments.

supported the recognition and/or protection of Indigenous Peoples' and local communities' rights.

provided a credible plan for addressing governance issues at national and sub-national levels.

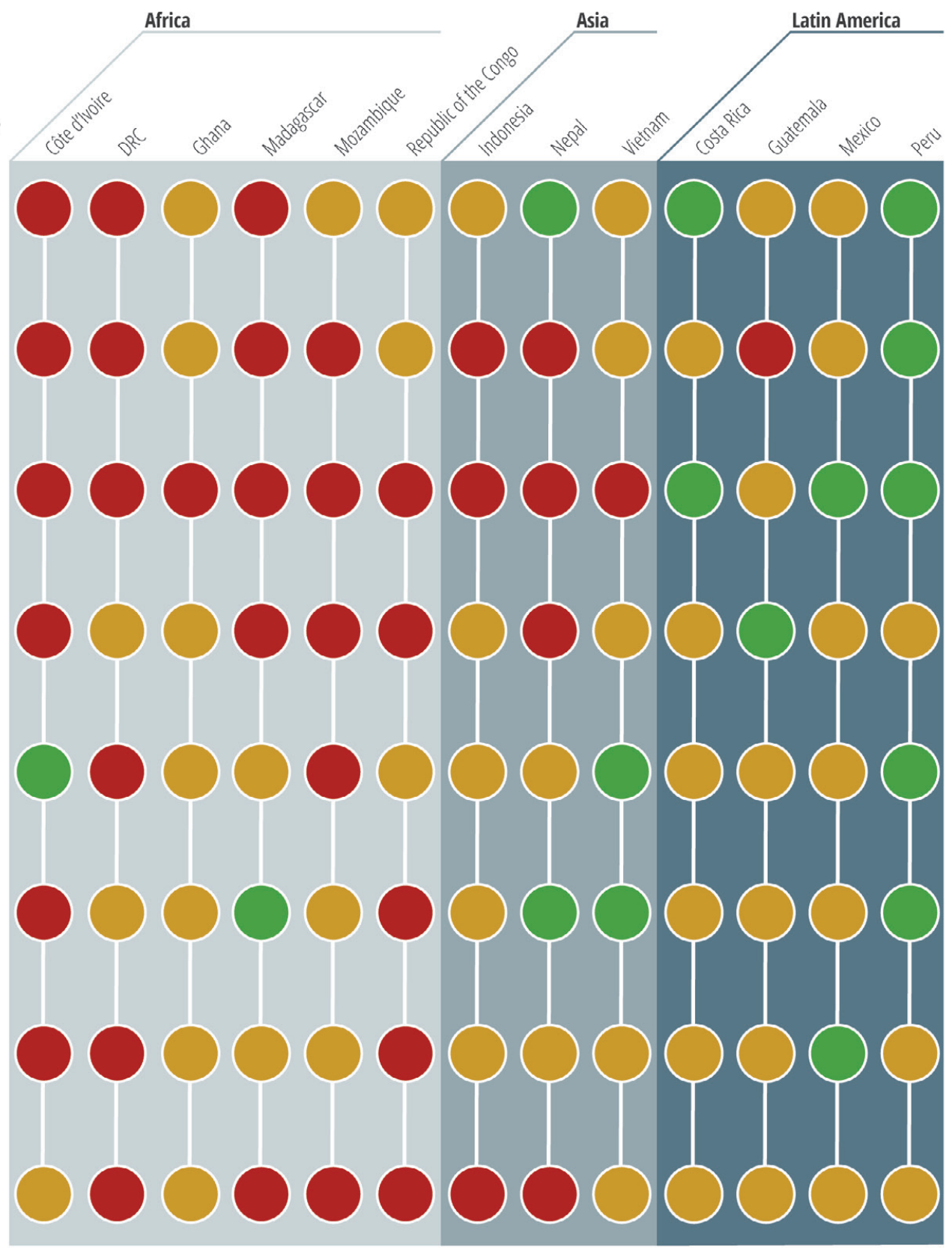

Key

The indicator is clearly addressed and supported by country stakeholders and other sources of evidence.

The indicator is partially addressed; ER-PIN claims are contested, and/or supporting evidence is weak.

The indicator is not addressed or is mentioned but not defined or explained, nor supported by evidence and local stakeholder input. 
documents were reviewed for this study were found to be weak in key factors for Indigenous Peoples' and local communities' rights and livelihoods, it is likely that the remaining 29-which will be submitting ER-PINs in the near future-are even less prepared. Recognizing the importance of locally-adapted institutions for achieving sustainable and equitable outcomes in the context of REDD+ initiatives is the essential first step.

As emphasized in this and other studies, securing tenure and resource rights and combating climate change are inseparable goals. To achieve such ends, a number of critical changes will need to be considered. RRI recommends that:

- Countries complete participatory land tenure assessments and develop time-bound action plans for the legal recognition and enforcement of collectively-held lands and territories.

- $\quad$ FCPF strengthens requirements for submissions to prevent countries from sidestepping critical readiness processes and ensure mandatory progress on key issues.

- $\quad$ FCPF requires the use of FPIC standards.

- FCPF relaxes intentions to treat carbon as a tradable asset, given the complexity of carbon rights.

- Gender-sensitive participatory measures and analyses be incorporated across FCPF procedures and funding requirements

- FCPF establishes clear guidelines for promoting engagement with local governments, Indigenous Peoples and local communities in national and subnational REDD+ processes.

- The Methodological Framework be thoroughly reviewed to assess the rigor of its application and alignment with the overall needs and concerns of forest communities, participating countries, and relevant UNFCCC guidelines.

These changes can provide a better starting point for REDD+ implementation that achieves the goal of reducing emissions from deforestation and forest degradation by respecting, protecting, and advancing the rights and livelihoods of forest communities. 


\section{Endnotes}

${ }^{1}$ UNFCCC secretariat. 2016. "Key decisions relevant for reducing emissions from deforestation and forest degradation in developing countries (REDD+)." United Nations Framework Convention on Climate Change. Available at: http://unfccc.int/land_use_and_climate_change/lulucf/items/6917.php.

2 Stevens, C., R. Winterbottom, J. Springer, and K. Reytar. 2014. Securing Rights, Combating Climate Change: How Strengthening Community Forest Rights Mitigates Climate Change. Washington, DC: World Resources Institute and Rights and Resources Initiative. Available at: www.wri.org/sites/default/files/securingrights-full-report-english.pdf.

${ }^{3}$ Rights and Resources Initiative. 2014a. Recognizing Indigenous and Community Rights: Priority Steps to Advance Development and Mitigate Climate Change. Washington, DC: RRI. Available at: http://www.rightsandresources.org/wp-content/uploads/Securing-Indigenous-and-Communtiy-Lands_Final_Formatted.pdf.

${ }^{4}$ Stevens et al. 2014.

${ }^{5}$ World Bank. 2010. Charter Establishing The Forest Carbon Partnership Facility. Available at: https://www.forestcarbonpartnership.org/sites/forestcarbonpartnership.org/files/Documents/PDF/Sep2010/FCPF Charter-August_2010_clean.pdf.

${ }^{6}$ Stevens et al. 2014

${ }^{7}$ Woods Hole Research Center and Environmental Defense Fund. 2015. Tropical Forest Carbon in Indigenous Territories: A Global Analysis. Available at: http://www.edf.org/sites/default/files/tropical-forest-carbon-in-indigenous-territories-a-global-analysis.pdf.

${ }^{8}$ Rights and Resources Initiative. 2016. Closing the Gap: Strategies and scale needed to secure rights and save forests. Washington, DC: RRI. Available at: http://rightsandresources.org/en/publication/closing-the-gap.

${ }^{9}$ Stevens et al. 2014.

10 Oxfam, International Land Coalition, Rights and Resources Initiative. 2016. Common Ground: Securing Land Rights and Safeguarding the Earth. Oxford: Oxfam. Available at: http://rightsandresources.org/en/publication/global-call-common-ground.

11 Williams and Davis. 2012. Getting Ready with Forest Governance: A Review of the Forest Carbon Partnership Facility Readiness Preparation Proposals and the UN-REDD National Programme Documents, v 1.9. WRI Working Paper. Washington DC: World Resources Institute; Global Witness. 2010. Review of JPDs and R-PPs Submitted to the 4th UNREDD Policy Board and 5th FCPF Participants Committee Meetings. Available at: https://www.globalwitness.org/sites/default/files/rpp\%20\%26jpd\%20assessments\%20mar-10\%5Bargentina\%20 bolivia\%20drc\%20ghana\%20madagascar\%20mexico\%20suriname\%20zambia\%5D_0.pdf.

Additional Global Witness R-PP reviews can be found at the FCPF website. Additional sources consulted to develop the assessment can be found in the country reports at: www.rightsandresources.org/erpins2016.

${ }^{12}$ Additional input for the design of the analytical framework includes World Bank operational policies and procedures, the general conditions and commercial terms of the emission reduction payment agreements, and FCPF-specific guidance such as the Common Approach, the joint FCPF/UN-REDD stakeholder engagement guidelines, and the FCPF guidance on disclosure of information. Feedback from FCPF's Facility Management Team (FMT) was sought on both the MF and country assessments, but other than minor clarifications from the FMT legal team, no substantive comments were received.

${ }^{13}$ Forest Carbon Partnership Facility. 2015. Setting the Stage for ER-PIN Reviews. Available at: https://www.forestcarbonpartnership.org/sites/fcp/files/2015/October/CF13\%202a.\%20Setting\%20the\%20stage\%20 for\%20ER-PIN\%20reviews_1.pdf.

${ }^{14}$ Also referred to as "accounting area" in the FCPF and MF guidance.

15 USAID. 2013. Ghana - USAID Country Profile, Property Rights and Resource Governance. Available at: http://usaidlandtenure.net/sites/default/files/country-profiles/full-reports/USAID_Land_Tenure_Ghana_Profile_0.pdf.

${ }^{16}$ See Section 5.1 and Criterion 28 of the MF.

${ }^{17}$ In the CF guidance, stakeholder engagement is to be initiated or strengthened during the Readiness phase, leading to the development of a consultation and participation plan in the R-PP and the SESA process, which in turn was intended to produce ongoing multi-stakeholder dialogues to develop and refine a national REDD+ strategy.

${ }^{18}$ Biermann, et al. 2012. Transforming governance and institutions for global sustainability: key insights from the Earth System Governance Project. Current Opinion in Environmental Sustainability, 4(1), 51-60; Ostrom, E. 2009. A Long Polycentric Journey, Annual Reviews: 34: 253-278. 
19 Parrotta et al. 2012. Traditional Knowledge Contributes to Sustaining Forests and Biocultural Diversity. Bois et Forêts des Tropiques. 312 (2): 3-7.

20 The rationale for Element 4 of the guiding principles (p.8) states: Although the World Bank policy does not expressly refer to "free prior and informed consent (FPIC)" per se, if the country has ratified ILO Convention No.169 and adopted national legislation on FPIC, or if the Bank is working on an ER-Program with a development partner that expressly applies the principle of FPIC, the Bank should in turn require the application to the ER-Program of ILO Convention 169 in that country, or should agree to the development partner's application of its provisions pertaining to FPIC in that country or for that ER-Program.

${ }^{21}$ Silverman, Allison. 2015. Using International Law to Advance Women's Tenure Rights in REDD+. Edited by Niranjali Amerasinghe. Washington, DC: Rights and Resources Initiative and Center for International Environmental Law. Available at: http://www.ciel.org/wp-content/uploads/2015/06/WomensTenureRights_REDD_June2015.pdf.

22 Larson, A.M. et al. 2015. "The role of women in early REDD+ implementation: lessons for future engagement." International Forestry Review 17(1): 43-65.

${ }^{23}$ Rights and Resources Initiative and Ateneo School of Government. 2014. Status of Forest Carbon Rights and Implications for Communities, the Carbon Trade, and REDD+ Investments. Washington, DC: RRI. Available at: http://www.rightsandresources.org/wp-content/uploads/ForestCarbon_Brief-for-web-16Mar14.pdf.

${ }^{24}$ Rights and Resources Initiative. 2015. Looking for Leadership: New Inspiration and Momentum Amidst Crises. Washington, DC: RRI. Available at: http://rightsandresources.org/en/publication/looking-for-leadership-new-inspiration-and-momentum-amidst-crises.

25 This includes, but is not limited to, efforts to improve local livelihoods, forest governance, land tenure security, and biodiversity.

${ }^{26}$ For example, see: Meyfroidt et al., 2013. Globalization of land use: Distant drivers of land change and geographic displacement of land use. Current Opinion in Environmental Sustainability, 5(5), 438-444.

${ }^{27}$ Côte d'Ivoire, for example, referred to studies on drivers of deforestation from 2001 and Peru discussed deforestation trends based on data from 2000 to 2011.

* Report written and prepared by Alain Frechette, Josh Lichtenstein, and Sonia Saini. The analysis underpinning the report was produced by Josh Lichtenstein and Almeida Dohrn Consulting (Fernanda Almeida and Gustavo Ribeiro). We are grateful for additional inputs, valuable contribution, and feedback from Goril Andreassen, Julian Atkinson, Kysseline Cherestal, Simon Counsell, Chloe Ginsburg, Eulalie Guillaume, Arvind Khare, Cécile Ndjebet, Mary Nyuyinwi, Jenny Springer, Jennifer Schenk, Rodney Schmidt, and Andy White. 



\section{The Rights and Resources Initiative}

The Rights and Resources Initiative (RRI) is a global coalition consisting of 13 Partners, 4 Affiliated Networks, 12 International Fellows, and more than 150 international, regional, and community organizations dedicated to advancing the forest land and resource rights of Indigenous Peoples and local communities. RRI leverages the collaboration and expertise of coalition members to promote secure local land and resource rights and catalyze progressive policy and market reforms. For more information, please visit www.rightsandresources.org.

\section{Sponsors}

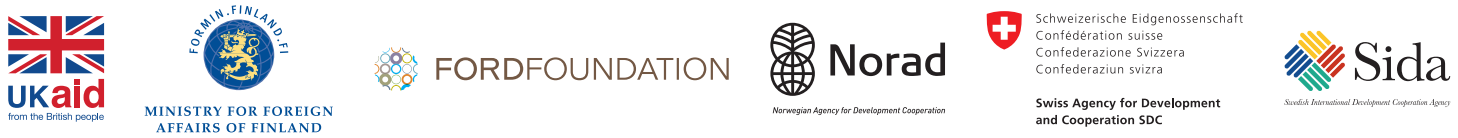

The views presented here are not necessarily shared by the agencies that have generously supported this work, or all of the Partners of the Coalition.

This work is licensed under a Creative Commons Attribution License CC BY 4.0.

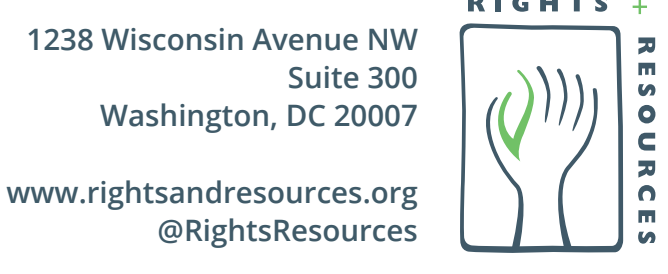

